\title{
Antimicrobial and bactericidal impacts of Bacillus amyloliquefaciens CECT 5940 on fecal shedding of pathogenic bacteria in dairy calves and adult dogs
}

\author{
Paulina Vazquez-Mendoza ${ }^{\mathrm{a}}$, Mona M.M. Elghandour ${ }^{\mathrm{b}}$, Peter Adeniyi Alaba ${ }^{\mathrm{c}}$, \\ Pedro Sánchez-Aparicio ${ }^{\mathrm{b}}$, María Uxúa Alonso-Fresán ${ }^{\mathrm{b}}$, Alberto Barbabosa-Pliego ${ }^{\mathrm{b}}$, \\ Abdelfattah Z.M. Salem ${ }^{\mathrm{b}, *}$ \\ ${ }^{a}$ Centro Regional de Educación Superior de la Costa Chica, Universidad Autónoma de Guerrero, Florencio Villarreal, Guerrero, Mexico \\ ${ }^{\mathrm{b}}$ Facultad de Medicina Veterinaria y Zootecnia, Universidad Autónoma del Estado de México, Mexico \\ ${ }^{\mathrm{c}}$ Department of Chemical Engineering, University of Malaya, 50603 Kuala Lumpur, Malaysia
}

\section{A R T I C L E I N F O}

\section{Keywords:}

Bacillus amyloliquefaciens

Calf

Dog

Faecal bacteria

Waste milk

\begin{abstract}
A B S T R A C T
Two experiments were carried out to evaluate the bactericidal impacts of Bacillus amyloliquefaciens CECT 5940 on the shedding of faecal pathogenic bacteria in dairy calves (Experiment 1) and in adults dogs (experiment 2). In the calves experiment, a completely randomized design was used to investigate the faecal bacteria profile of Holstein dairy calves fed with either pasteurized waste milk (PWM; $n=9)$ or a formulated non-medicated milk replacer (NMR; $\mathrm{n}=9$ ) for $60 \mathrm{~d}$. The NMR containing sodium-butyrate and the active probiotic B. amyloliquefaciens CECT 5940. In the dogs experiment, addition of same probiotic (i.e., B. amyloliquefaciens CECT 5940) was carried out in two stages. The first stage started from day 7-37, and the second from day 44-71. The assessment of faecal score measured on day 22, 37, 42, 57, 71 and 77 to determine the texture of the stools. Calves received PWM consumed $(\mathrm{P}<0.05)$ more starter feed between day 16 and day 45 . The calves fed NMR had more moisture faeces and less cough reflux than the PWM-calves. Feeding NMR to calves increased faecal Klebsiella oxytoca and Proteus vulgaris counts in comparison to PWM-calves. The administration of B. amyloliquefaciens CECT 5940 to the dog diet has no significant effect on the hardness of the stool. Meanwhile, the bacillus count increases while the coliforms count decreases upon B. amyloliquefaciens CECT 5940 administration. This reveals that B. amyloliquefaciens CECT 5940 survived the gastrointestinal passage and rapidly colonized the dog intestine, which could positively affect the metabolism and composition of the intestinal microflora. These results show that $B$. amyloliquefaciens are a promising probiotic with an antimicrobial and bactericidal activities against the intestinal pathogenic bacteria for dairy calves and adult dogs.
\end{abstract}

\section{Introduction}

In dairy calves, increasing interest is paid to dairy calf growth by improving the early life nutrition, based on increased liquid feeding to enhance calf survival and growth [1-3]. Waste milk is a non-saleable transition milk from cows or milk from cows treated with antibiotics. Waste milk is generally not suitable for human intake; however, it contains essential nutrients that can support calf growth. Godden et al. [2] showed in the USA that about 22-62 kg of waste milk is wasted per cow yearly. This lead to a large economic loss to the dairy industry. However, feeding raw non-saleable waste milk may pose risks for the transmission of infectious pathogens, such as Mycobacterium avium, Mycobacterium bovis, Listeria monocytogenes, Escherichia coli, Salmonella sp., Mycoplasma, and Campylobacter. Stabel et al. [4] reported that pasteurization is an active method to destroy common pathogenic bacteria species, presented in waste milk.

Non-medicated milk replacer (NMR) is widely used to replace whole milk for dairy calf feeding and can be manufactured with a variety of ingredients and levels of nutrient with additives, such as vitamins, antibiotics, coccidiostats, probiotics and ionophores to better support calf growth [1,5,6]. Elghandour et al. [7], in their review, reported less incidence and duration of diarrhea in calves that consumed probiotics (e.g. Saccharomyces cerevisiae, Bacillus amyloliquefaciens and Saccharomyces boulardii), which may reduce mortality and morbidity of neonatal calves as a result of reduction of pathogenic bacteria such as Salmonella and E. coli [8]. Supplementation with probiotic may accelerate the formation of intestinal and ruminal microorganisms and reduce the formation of enteropathogens, which often cause diarrhea [7].

\footnotetext{
* Corresponding author.

E-mail address: asalem70@yahoo.com (A.Z.M. Salem).
} 
Probiotics also confer a health benefit to dogs. The mechanisms of action include regulation of microbial homeostasis in the intestine, stabilization of the gastrointestinal barrier, expression of bacteriocins, an enzymatic activity that enhances nutrient digestibility, immune modulator effects, and interference with the ability of pathogens to bind to the intestinal wall [9]. Moreover, the normal composition of the intestinal microflora in dogs can be altered by hectic conditions, such as oral administration of antibiotics, gastrointestinal infections, dietary changes, and weaning.

In this context, the addition of a probiotic to the diet of pets is a way to improve intestinal health, preventing gastrointestinal disorders, and as a consequence, improving coexistence with the owners. In this vein, Buddington et al. [10], demonstrated that a combination of B. amyloliquefaciens and $E$. faecium decreases the concentration of Clostridium spp. pathogen. The ability of Bacillus to survive through the digestive process, germination within the digestive tract, and defecation via faecal matter makes it the most promising [11].

B. amyloliquefaciens is a strong strain of Bacillus, which is capable of producing extracellular enzymes like cellulase, proteases, metalloproteases, and a-amylases. These enzymes help to boost the efficiency of absorption and digestion of nutrients [12]. Furthermore, bacteriocins such as barnase and subtilin generated by $B$. amyloliquefaciens exhibit antibacterial activity against pathogenic bacteria [13]. In recent times, a number of studies have established that dietary supplementation of B. amyloliquefaciens boost intestinal microflora, gut morphology, and nutrient digestibility, thereby enhancing the growth rate and feed efficiency $[14,15]$. These positive effects indicated that the $B$. amyloliquefaciens could also improve the health status of calves and dogs.

Therefore, the objective of this work is to evaluate the impact of Bacillus amyloliquefaciens CECT 5940 on some pathogenic bacteria shedding in dairy calves and adults dogs feed intake, body weight [16] gain, and health conditions of Holstein calves fed with PWM and those fed with NMR containing sodium-butyrate and active B. amyloliquefaciens for $60 \mathrm{~d}$. For a bacterium to be a viable probiotic, it must be capable of surviving the acidic conditions of the intestinal tract and colonizing or replicating in the large intestine freely. Although there are several conventional probiotic supplements that can be used for dogs, there are yet few controlled studies of the survival and influence of probiotics in dogs [17]. This study also assessed the effectiveness of $B$. amyloliquefaciens CECT 5940 supplementation in dog diet at a daily dose of $1 \times 10^{6} \mathrm{CFU} / \mathrm{g}$, and survivability as it passes through the gastrointestinal tract, colonizes the colon, and enhances the health status.

\section{Materials and methods}

\subsection{Experiment 1: Feeding of B. amyloliquefaciens CECT 5940 and shedding of faecal bacteria in diary calves}

This investigation was carried out on a commercial dairy farm in Pabellón Arteaga (Aguascalientes, Mexico), and all experimental procedures were performed according to the standard ethics of the official Mexican standard of animals care (NOM-051-ZOO-1995) and the 1964 Helsinki declaration and its subsequent revision for comparable ethical standards.

\subsubsection{Calves management and feeding}

Eighteen clinically healthy Holstein female calves with an initial body weight of $41 \pm 3.7 \mathrm{~kg}$, born without congenital malformations were detached from their mothers within $1-2 \mathrm{~h}$ from birth. Calves were identified with an ear tag (Intelitec ${ }^{\circ}$, Intelitec S.A. de C.V., Mexico) and fed colostrum (colostrum was pooled and then fed individually per calf) by bottle (immunoglobins $\mathrm{G}$ (IgG); 70-100 mg/mL; analysed according to [18] within the first $2 \mathrm{~h}$ of life at the rate of $10 \%$ of their body weight. Calves were then fed with $2 \mathrm{~L}$ colostrum every $12 \mathrm{~h}$ for three days as a sole feed. Animals were accommodated in individual metal pens $(1.2 \mathrm{~m} \times 1.5 \mathrm{~m})$ bedded with sawdust, for an experimental period of $60 \mathrm{~d}$. Calves were randomly allotted to one of two dietary treatments: pasteurized waste milk (PWM; $\mathrm{n}=9$ ) or formulated non-medicated milk replacer (NMR; $n=9$ ). The PWM used is raw milk obtained from cows treated with antibiotics in addition to the accumulated non-saleable, transition milk and colostrum. The raw waste milk was heated to $70{ }^{\circ} \mathrm{C}$ for $15 \mathrm{sec}$ and then cooled to $38{ }^{\circ} \mathrm{C}$ prior to feeding.

The milk replacer contained ( $\mathrm{g} / \mathrm{kg}$ dry matter (DM)): whey (471.0), concentrated whey protein (52.8), pork fat (266.3), lactose (100.0), soy protein isolate (100.0), lecithin SOLEC 3F-UB (3), vitamins and minerals (0.4), Allura red AC dye (0.5) and sodium-butyrate (6) plus a probiotic (1) of active B. amyloliquefaciens CECT 5940 at $1 \times 10^{6} \mathrm{CFU} /$ $\mathrm{g}$ DM of probiotic (ECOBIOL ${ }^{\circ}$, Evonik Industries de Mexico SA de CV). At every feeding time, NMR solution was prepared in steel buckets by mixing $120 \mathrm{~g}$ of NMR powder with $1 \mathrm{~L}$ of warm water $\left(45^{\circ} \mathrm{C}\right)$. The NMR solution was then cooled to $38{ }^{\circ} \mathrm{C}$ before serving. The calves were fed individually twice daily at 0900 and $1600 \mathrm{~h}$ using the buckets throughout the study according to the following protocol: day 4-20; $2 \mathrm{~L}$ liquid, d 21 to 60; 3 L liquid per feeding per calf. On day 4, calves were offered pelleted starter feed (FOGASA, Aguascalientes, Mexico) once a day in the morning at $0900 \mathrm{~h}$. All the calves were giving fresh water ad libitum. The feed and water intake, weight gain and health conditions for each calf were observed.

\subsubsection{Measurements and observations}

The calves were weighed with a digital plate scale (Torrey ${ }^{\circledR} \mathrm{EQM}$, México) on day 1, 15, 30, 45 and 60 of the experimental period. The height of the calf (hoof to the back) was measured with a wooden ruler (Garrott-Metre , Pro-Vac Inc., Canada) on day 1, 15, 30, 45 and 60.

A faecal sample of $10 \mathrm{~g}$ per calf was obtained directly from the rectum of each calf on day 1,30 and 60 . The samples were immediately referred to the laboratory where plantings were done in a selective media, differential and enriched anaerobically at $37{ }^{\circ} \mathrm{C}$ for $72 \mathrm{~h}$ to quantify the colony-forming unit/g of $E$. coli (plated on sorbitol MacConkey agar supplemented with cefixime and potassium tellurite; [19]. K. oxytoca and K. pneumoniae (plated on Simmon's citrate agar with $1 \%$ inositol [20], P. mirabilis and P. vulgaris (plated in a medium contained heart infusion agar supplemented with bile salts, lithium chloride, sodium thiosulfate, and sodium citrate [21]; were also evaluated. The calves health were monitored daily, and the rating of individual calf faeces was scored as 1 (normal), 2 (pasty), 3 (semi) and 4 (liquids).

\subsubsection{Statistical analysis}

The PROC MIXED of SAS (version 9.0; SAS Institute, 2002) was used for statistical analysis. The model contained "individual calf" as a random effect and "dietary treatment" (PWM or NMR (contain the B. amyloliquefaciens CECT 5940)) as a fixed effect. All analyses were performed individually, with verification that the convergence criterion was met, with the following model.

$\mathrm{Y}_{\mathrm{ij}}=\mu+\mathrm{T}_{\mathrm{i}}+\mathrm{E}_{\mathrm{ij}}$

where $Y_{i j}$ is every observation of the $j$ th calf assigned to ith treatment, $\mu$ is the overall mean, $T_{i}$ is the treatment effect, and $E_{i j}$ is the residual error.

To separate the least square means, the PDIFF SAS option was used; $\mathrm{P}<0.05$ was declared as statistically significant.

\subsection{Experiment 2: Feed of B. amyloliquefaciens and shedding of faecal bacteria in adult dogs}

The experiment was carried out considering the animal welfare standards of NOM 062 ZOO 1999 "Technical specifications for the production, care and use of laboratory animals". 


\subsubsection{Dogs feeding and management}

The dogs were housed in an individual kennel at a constant temperature of $22{ }^{\circ} \mathrm{C}$, from the Center for Research in Pet Food (CIAM) located in Tepeji del Rio de Ocampo, Hidalgo, Mexico. The kennels were equipped with a wooden platform for the rest of the animals and had fresh water all the time.

Eight dogs were clinically healthy (Bichon Frize, 5 males, and 3 females) and were randomly assigned to two treatments group. The first is control group (without addition of B. amyloliquefaciens CECT 5940, $\mathrm{n}=4$, live weight: $5.76 \pm 1.49 \mathrm{~kg}$ ). The second is probiotic group (with addition of B. amyloliquefaciens CECT 5940, $\mathrm{n}=4$, live weight: $4.93 \pm 0.56 \mathrm{~kg}$ ) and the standard diet supplemented with the same probiotic product used in the 1 st experiment (i.e., B. amyloliquefaciens CECT 5940, $1 \times 10^{9} \mathrm{CFU} / \mathrm{g}$ DM of product (ECOBIOL', Evonik Industries de Mexico SA de CV)). The feed was made with commercial feed based on poultry, beef and pork meal, milled corn, soybean paste and rice (Dog Chow adults small breeds; Nestlé Purina PetCare, Mexico) with a nutritional contribution (\%): crude protein (23), ethereal extract (12), crude fiber (4), ash (8)). The amount of feed offered per day was calculated according to live weight following the recommendations of the NRC [22]. Feed intake and probiotic supplementation were monitored daily.

\subsubsection{Experimental periods and probiotic supplementation}

The animals were housed individually, fed once a day, the experimental period was 30 days, with six days of previous adaptation (PP, the period before addition of B. amyloliquefaciens CECT 5940) and seven days of rest. From day 7-37 (EP, an experimental period during the addition of B. amyloliquefaciens CECT 5940) supplemented with the probiotic offering the amount equivalent to $1 \mathrm{~g}$ of probiotic per $\mathrm{kg}$ of food, with the aim of offering the dog a dose of $1 \times 10^{6} \mathrm{CFU} / \mathrm{g}$ to the food. The probiotic was added to the ration (on top) before being offered. The probiotic comes in an odorless white powder, which facilitated its application. At day 37, the probiotic supplementation was withdrawn for $7 \mathrm{~d}$, then the same procedure was replicated by changing the animals from the control (i.e., without $B$. amyloliquefaciens CECT 5940 ) group to the probiotic group (i.e. with B. amyloliquefaciens CECT 5940). The dosage of the treated food from day 44-71 was reinstalled (FP, experimental final period after adding the B. amyloliquefaciens CECT 5940) and from day 72 to the last collection of faeces (day 77, final period) food was given without probiotic.

\subsubsection{Faecal microbial count}

The first fresh faeces of the day were collected immediately after the deposition of each animal during PP (day 7), EP (days 22 and 37) and FP (day 42) and in the second stage faeces were collected in EP days 57 and 71) and FP (day 77). The samples were refrigerated and transported in a maximum of $1 \mathrm{~h}$ to the microbiology laboratory of the Faculty of Higher Studies Cuautitlán-UNAM. $1 \mathrm{~g}$ of a stool sample from each period was taken and homogenized at $1 \%$ in a sterile $(\mathrm{w} / \mathrm{v})$ phosphate medium and serially diluted to $10-9$. In duplicate, $100 \mu \mathrm{L}$ of this suspension was taken and spread in a selective medium: Mac Conkey agar (Dibico S.A. of C.V. Mexico D.F.) for total Enterobacteria and E. coli. Petri dishes were incubated anaerobically (GasPak BBL anaerobiosis jar, Becton Dickinson, NJ, USA) at $37{ }^{\circ} \mathrm{C}$ for $48 \mathrm{~h}$. For the quantification of $B$. amyloliquefaciens the same procedure was followed, $100 \mu \mathrm{L}$ in duplicate were seeded in a selective medium: Soya agar and Tripticaseina (Dibico SA de CV Mexico DF) enriched with $0.2 \%(\mathrm{w} / \mathrm{v}$ ) starch and incubated at $37{ }^{\circ} \mathrm{C}$ for $48 \mathrm{~h}$, then counted visually. For Clostridium spp. in duplicate, $100 \mu \mathrm{L}$ of the suspension was taken and seeded in boxes with selective medium: Tryptose sulfite Cycloserine agar (Becton Dickinson, NJ, USA) were incubated with anaerobiosis at $37{ }^{\circ} \mathrm{C}$ for $48 \mathrm{~h}$.

\subsubsection{Dogs stool quality measurements}

Stool consistency was measured during the evaluation periods (i.e.,
PP, PE, PF) in the two treatment application orders (i.e. CON-PRO, PRO-CON) 5 times per week using the illustrated Nestlé Purina rating system. Faeces were scored on a 1-7 scale in which Grade 1 represents hard stools and Grade 7 represents liquid stools.

\subsubsection{Statistical analysis}

The microbiological count, stool score, Microsporum canis culture and live weight was statistically evaluated using a completely randomized design with repeated measures over time. The main effects will be the treatments (control) and Probiotic and sampling time (PP, Ep, FP), and the interaction between treatment and time. The analysis of variance was done using the GLM procedure of Minitab $16^{\circ}$ to detect the differences. The means were compared with the Tukey test $(\alpha=0.05)$.

\section{Results and discussion}

\subsection{Effect of B. amyloliquefaciens CECT 5940 on faecal bacteria in diary} calves

After $30 \mathrm{~d}$ of the experiment, PWM-calves had higher faecal $E$. coli than NMR-calves (B. amyloliquefaciens CECT 5940 supplemented). However, NMR-calves had faecal $K$. oxytoca and $P$. vulgaris. Both $P$. vulgaris and $K$. oxytoca emerged at the day 1 of the experiment and then disappeared from samples from day 30-60 in PWM-calves. $K$. pneumoniae was not found in PWM-calves at day 60, while for NMRcalves, it disappeared both on day 30 and 60 (Fig. 1).

The initial BW, colostrum IgG and total serum protein concentrations of the calves are similar, indicating that the differences in performance exhibited by the calves are not related to the differences in the health status of the calves at the beginning of the study. However, the NMR-calves, which was supplemented with $B$. amyloliquefaciens CECT 5940 had higher faecal score and lower cough score than PWMcalves (Fig. 2). The improved immune system with PWM-calves is clearly observed, as the faecal score was decreased compare to NMRcalves.

Throughout the experimental period, calves fed NMR had higher content from $P$. vulgaris and $K$. oxytoca with a similar count of $E$. coli than calves fed on PWM. This could be ascribed to the presence of antibiotics in the PWM since the used PWM came from cows treated with antibiotics. Moreover, based on the waste milk content, the PWM contains higher concentrations of a protective immunoglobulin such as IgG, IgA, and IgM. PWM exhibit nonspecific immune factors like leukocytes, cytokines, growth factors, hormones, vitamins, lactoferrin, and lysozyme than the NMR [2]. Moreover, the medium-chain fatty acids with a strong antimicrobial effects are abundant in milk fat but are mostly absent from the mixture of fats used in most milk replacers [2]. Lee et al. [1] observed no differences in the health of calves without mortality during their study, when claves were fed on whole milk or NMR for $70 \mathrm{~d}$.

\subsection{Effect of B. amyloliquefaciens CECT 5940 on shedding of faecal bacteria in dogs}

The control and probiotic-supplemented foods had slightly different water contents. No Bacillus counts were observed for both the supplemented and control diets until day 22 where $>3 \times 10^{7} \mathrm{CFU} / \mathrm{g}$ and $>10^{4} \mathrm{CFU} / \mathrm{g}$, respectively were observed. At the end of the study, $>2 \times 10^{5} \mathrm{CFU} / \mathrm{g}$ and $>10^{4} \mathrm{CFU} / \mathrm{g}$, respectively were observed. Daily probiotic intake for the dogs during the probiotic phase was aimed to be $1 \times 10^{6} \mathrm{CFU} / \mathrm{g}$ daily. This result shows that B. amyloliquefaciens CECT 5940 can be added to dog diet effectively. The $B$. amyloliquefaciens survived the movement through the gastrointestinal tract of the dog and rapidly colonized the dog's intestine, resulting in enrichment of colonic microflora and systemic and local effects [23]. The local effect entails an increase in Bacillus count and a 


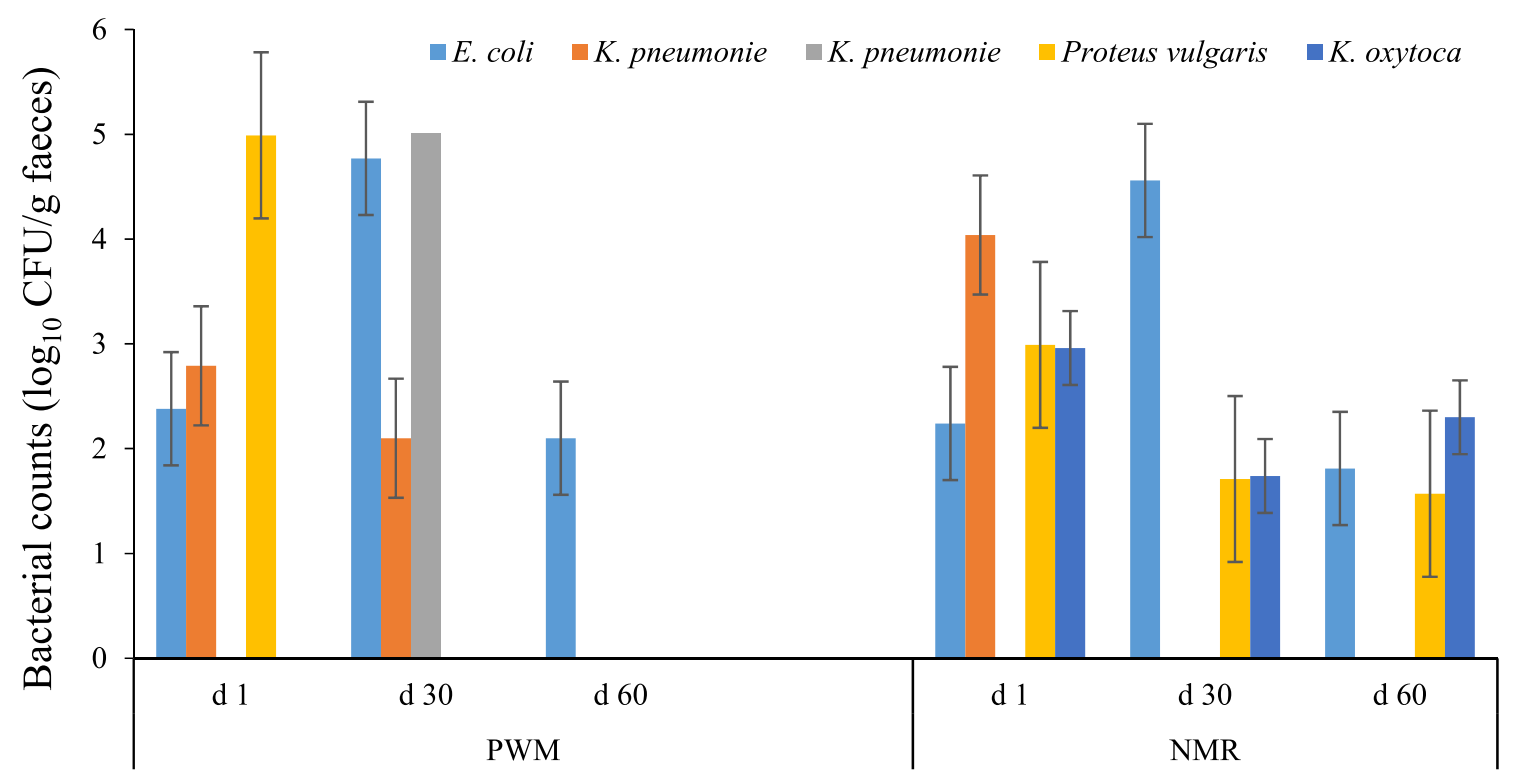

Faecal bacteria

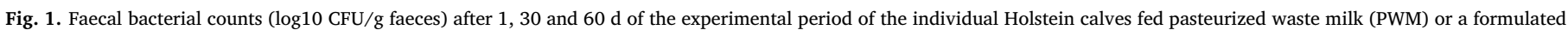
non-medicated milk replacer (NMR) contained Bacillus amyloliquefaciens CECT 5940 for $60 \mathrm{~d}$.

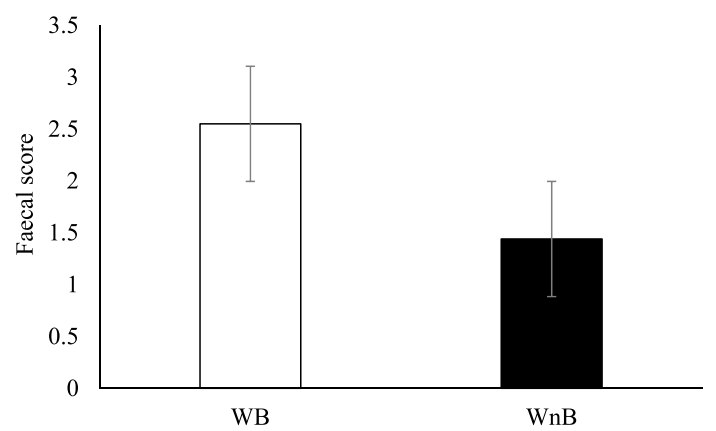

Fig. 2. Scores of Holstein calves faecal cultures in the presence of dietary B. amyloliquefaciens CECT 5940. WB: with Bacillus, WnB: without Bacillus. decrease in coliform count. The systemic effect was observed in several immunologic and hematologic parameters. No significant change was observed in the mean faecal score of the supplemented and the control diet throughout the period of the experiment (Fig. 3).

Fig. 4 presents the Bacillus count for the supplemented and the control diet. The Bacillus count of the supplemented diet is significantly higher than that of the control diet. The highest Bacillus count was observed on day 22, the Bacillus count decreases significantly after day 37, while it increases after day 44.

The significantly high Bacillus count in the supplemented diet is attributed to the resistance of the probiotics to the production process [17]. This makes the actual Bacillus concentration in the diet $\left(>3 \times 10^{7} \mathrm{CFU} / \mathrm{g}\right)$ to surpass the predicted value in the recipe $\left(1 \times 10^{6} \mathrm{CFU} / \mathrm{g}\right)$. However, this value decreased to about $2 \times 10^{5} \mathrm{CFU} / \mathrm{g}$ at the end of the experiment. Extreme care was ensured in the production and storage of probiotics-supplemented diet to prevent exposure to air, thereby maintaining lower moisture content than the control diet. This was achieved by storing the supplemented diet in

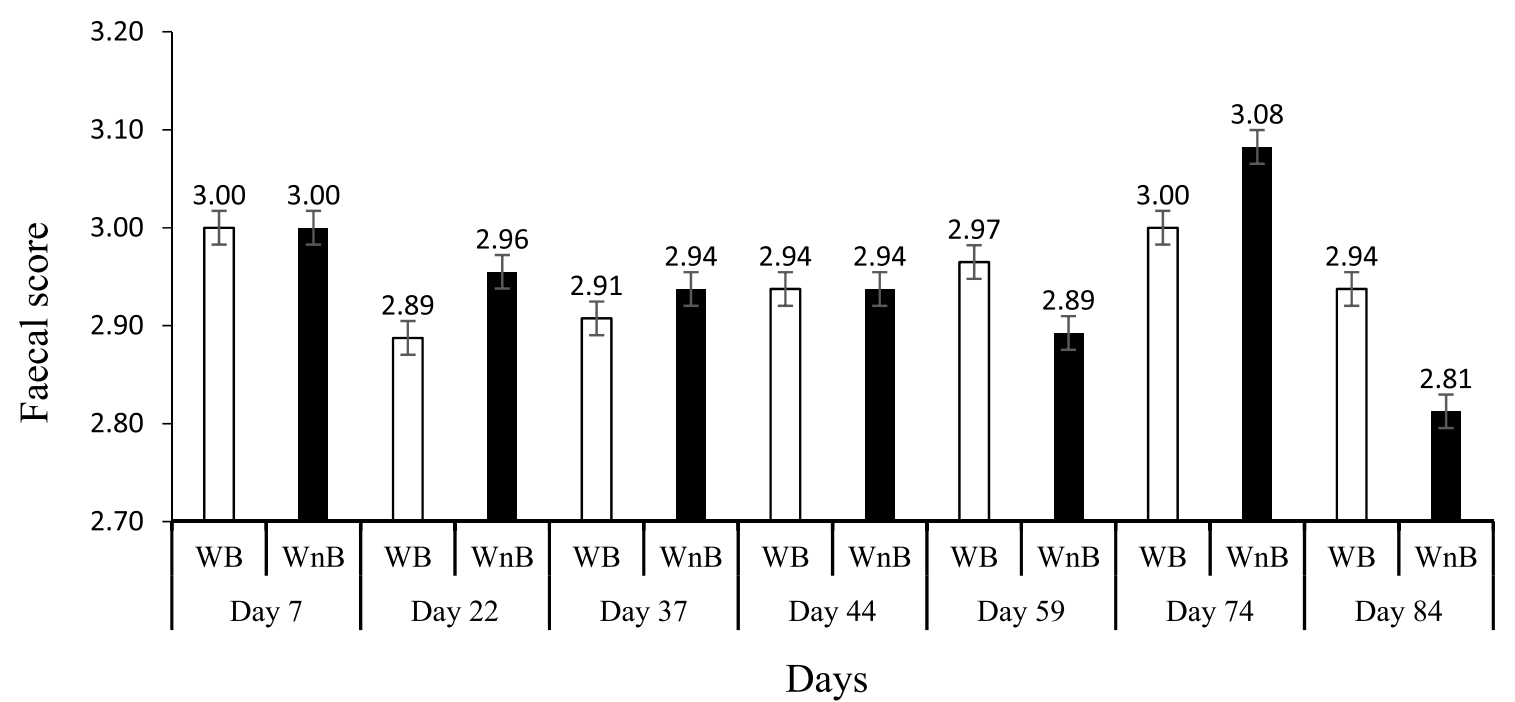

Fig. 3. Scores of dog faecal cultures in the presence of dietary B. amyloliquefaciens CECT 5940. WB: with Bacillus, WnB: without Bacillus. 


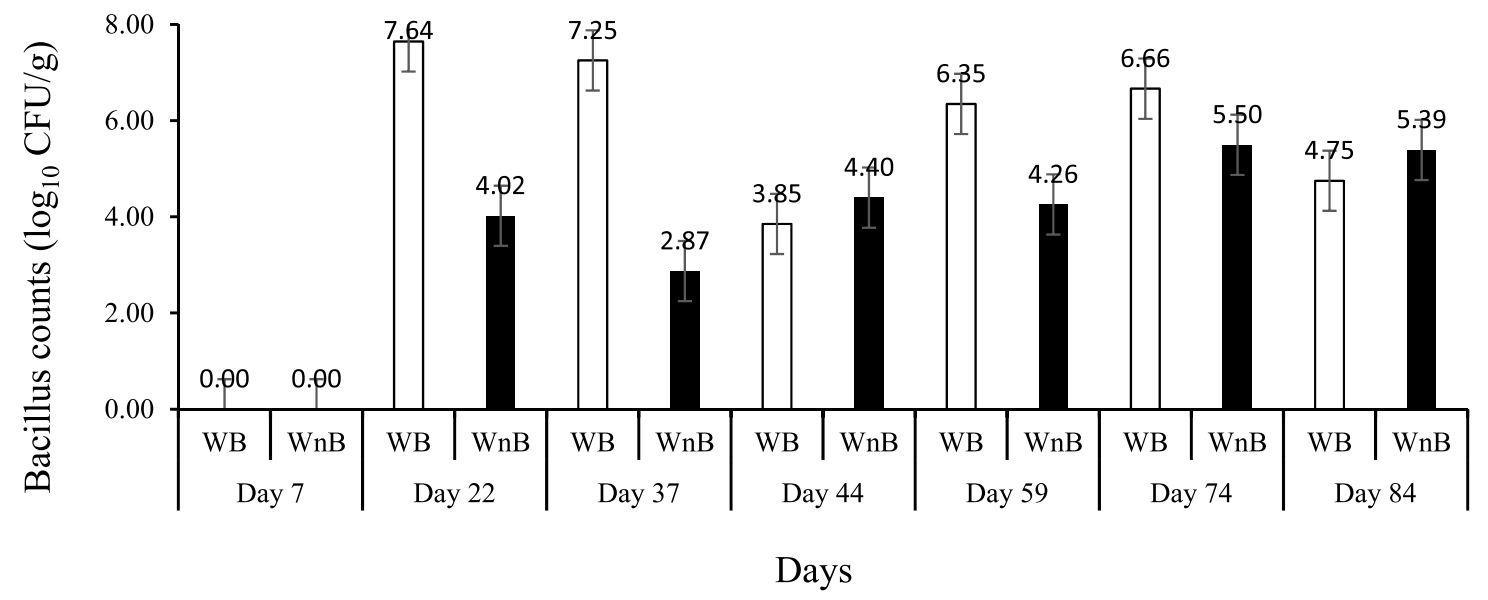

Fig. 4. Counts $\left(\log _{10} \mathrm{CFU} / \mathrm{g}\right)$ of viable bacillus in dog faecal cultures in the presence of dietary B. amyloliquefaciens CECT 5940. WB: with Bacillus, WnB: without Bacillus.

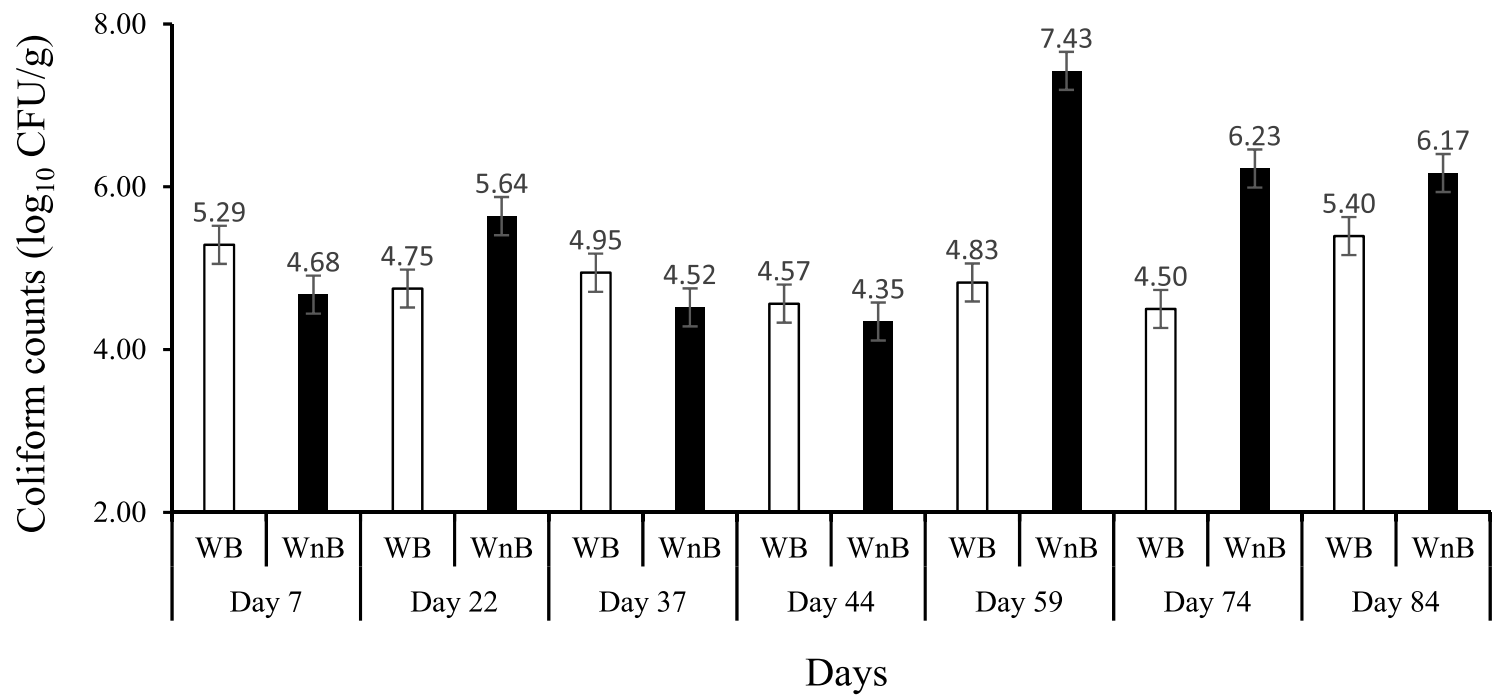

Fig. 5. Counts $\left(\log _{10} \mathrm{CFU} / \mathrm{g}\right)$ of viable coliforms in dog faecal cultures in the presence of dietary B. amyloliquefaciens CECT 5940. WB: with Bacillus, WnB: without Bacillus.

aluminum bags instead of using paper sacks, making the recoveries greater than those reported in previous studies [24]. Therefore, B. amyloliquefaciens CECT 5940 may not survive under production and storage condition other than the one used in this study. Exclusion of B. amyloliquefaciens CECT 5940 from the diet significantly reduced the Bacillus count due to the clearance of the probiotic bacteria from the colon. This is vivid in Fig. 5 on day 84.

The effect was visible on Soya agar and Tripticaseina. The total number of coliforms were measured selectively (Fig. 5). At the beginning of the experiment, the supplemented diet exhibits the highest coliform count compared with the control diet, while the control diet shows the highest at the end of the experiment (day 84). This shows that the supplemented diet is healthier than the control diet. Coliforms are faecal bacteria found in the digestive tracts of dogs. Water pollution caused by these bacteria is capable of causing serious illness. Although, most coliforms are not harmful, some rare E. coli strain (especially 0157:H7 strain) are deadly. E. coli $0157:$ H7 is commonly found in sheep, cattle, pigs and chickens.

\section{Conclusion}

The study explored the effect of B. amyloliquefaciens CECT 5940 addition to dairy calves and dogs' diet on the calves and dogs performance. Feeding NMR to calves increased faecal $K$. oxytoca and $P$. vulgaris counts in comparison to PWM-calves with more moisture in faeces. The overall results indicate that NMR contained B. amyloliquefaciens CECT 5940 could be used as a replacement product to substitute PWM and improve the shedding of intestinal bacteria without negative effects on calf health.

The administration of the same probiotic (i.e., B. amyloliquefaciens CECT 5940) to the dog diet has no significant effect on the hardness of the stool. Meanwhile, the Bacillus count increases while the coliforms count decreases upon B. amyloliquefaciens CECT 5940 administration. This reveals that B. amyloliquefaciens CECT 5940 survived the gastrointestinal passage and rapidly colonized the dog intestine, which could positively affect the metabolism and composition of the intestinal microflora. These results show that B. amyloliquefacien CECT 5940 is a promising probiotic with antimicrobial and bactericidal activities for dairy calves and adult dogs.

\section{Ethical approval}

All procedures performed in studies involving human participants were in accordance with the ethical standards of the official Mexican standard of animals care (NOM-051-ZOO-1995) and with the 1964 Helsinki declaration and its later amendments or comparable ethical standards." 


\section{Conflicts of interest}

All authors declare that there are no present or potential conflicts of interest among the authors and other people or organizations that could inappropriately bias their work.

\section{References}

[1] H. Lee, M. Khan, W. Lee, S. Yang, S. Kim, K. Ki, H. Kim, J. Ha, Y. Choi, Influence of equalizing the gross composition of milk replacer to that of whole milk on the performance of Holstein calves, J. Anim. Sci. 87 (2009) 1129-1137.

[2] S.M. Godden, J.P. Fetrow, J.M. Feirtag, L.R. Green, S.J. Wells, Economic analysis of feeding pasteurized nonsaleable milk versus conventional milk replacer to dairy calves, J. Am. Vet. Med. Assoc. 226 (2005) 1547-1554.

[3] J.K. Drackley, Accelerated Growth and Milk Replacers for Dairy Calves: Risks and Rewards, (2003).

[4] J. Stabel, S. Hurd, L. Calvente, R. Rosenbusch, Destruction of Mycobacterium paratuberculosis, Salmonella spp., and Mycoplasma spp. in raw milk by a commercial on-farm high-temperature, short-time pasteurizer, J. Dairy Sci. 87 (2004) 2177-2183.

[5] A. Heinrichs, C. Jones, B. Heinrichs, Effects of mannan oligosaccharide or antibiotics in neonatal diets on health and growth of dairy calves, J. Dairy Sci. 86 (2003) 4064-4069.

[6] J. Wagenaar, J. Langhout, Practical implications of increasing 'natural living'through suckling systems in organic dairy calf rearing, NJAS-wageningen J. Life Sci. 54 (2007) 375-386.

[7] M.M. Elghandour, A.Z. Salem, J.S.M. Castañeda, L.M. Camacho, A.E. Kholif, J.C.V. Chagoyán, Direct-fed microbes: a tool for improving the utilization of low quality roughages in ruminants, J. Integr. Agric. 14 (2015) 526-533.

[8] F.D.C.P. Tiago, F.D.S. Martins, E. Souza, P.F.P. Pimenta, H.R.C. Araújo, I.D.M. Castro, R.L. Brandão, J.R. Nicoli, Adhesion to the yeast cell surface as a mechanism for trapping pathogenic bacteria by Saccharomyces probiotics, J. Med. Microbiol. 61 (2012) 1194-1207.

[9] F. Gaggia, P. Mattarelli, B. Biavati, Probiotics and prebiotics in animal feeding for safe food production, Int. J. Food Microbiol. 141 (2010) S15-S28.

[10] K.K. Buddington, R.C. Cooper, S. Pierzynowski, K. Lehman, G. Swaggart, J. Donahoo, R. Buddington, A non-terminal surgical procedure for chronic collection of exocrine pancreatic secretions from unrestrained dogs (Canis familiaris). J. Am. Assoc. Lab. Anim. Sci. 41(1), 31-37.
[11] Y. Li, H. Zhang, Y.P. Chen, M.X. Yang, L.L. Zhang, Z.X. Lu, Y.M. Zhou, T. Wang, Bacillus amyloliquefaciens supplementation alleviates immunological stress in lipopolysaccharide-challenged broilers at early age, Poult. Sci. 94 (2015) 1504-1511.

[12] R.Y. Tang, Z.L. Wu, G.Z. Wang, W.C. Liu, The effect of Bacillus amyloliquefaciens on productive performance of laying hens, Italian J. Animal Sci. (2017) 1-6 https:// doi.org/10.1080/1828051X.2017.1394169.

[13] M.P. Lisboa, D. Bonatto, D. Bizani, J.A. Henriques, A. Brandelli, Characterization of a bacteriocin-like substance produced by Bacillus amyloliquefaciens isolated from the Brazilian Atlantic forest, Int. Microbiol. 9 (2010) 111-118.

[14] J.D. Latorre, X. Hernandez-Velasco, L.R. Bielke, J.L. Vicente, R. Wolfenden, A. Menconi, B.M. Hargis, G. Tellez, Evaluation of a Bacillus direct-fed microbial candidate on digesta viscosity, bacteria translocation, microbiota composition and bone mineralisation in broiler chickens fed on a rye-based diet, Brit. Poult. Sci. 56 (2015) 723-732.

[15] Y. Li, H. Zhang, Y.P. Chen, M.X. Yang, L.L. Zhang, Z.X. Lu, Y.M. Zhou, T. Wang, Bacillus amyloliquefaciens supplementation alleviates immunological stress and intestinal damage in lipopolysaccharide-challenged broilers, Anim. Feed Sci. Technol. 208 (2015) 119-131.

[16] J.C. Ssempebwa, D.O. Carpenter, The generation, use and disposal of waste crankcase oil in developing countries: a case for Kampala district, Uganda, J. Hazard. Mater. 161 (2009) 835-841.

[17] M.-L.A. Baillon, Z.V. Marshall-Jones, R.F. Butterwick, Effects of probiotic Lactobacillus acidophilus strain DSM13241 in healthy adult dogs, Am. J. Vet. Res. 65 (2004) 338-343.

[18] K. Morrill, E. Conrad, J. Polo, A. Lago, J. Campbell, J. Quigley, H. Tyler, Estimate of colostral immunoglobulin G concentration using refractometry without or with caprylic acid fractionation, J. Dairy Sci. 95 (2012) 3987-3996.

[19] P. Chapman, C.A. Siddons, P. Zadik, L. Jewes, An improved selective medium for the isolation of Escherichia coli O 157, J. Med. Microbiol. 35 (1991) 107-110.

[20] E. Van Kregten, N. Westerdaal, J. Willers, New, simple medium for selective recovery of Klebsiella pneumoniae and Klebsiella oxytoca from human feces, J. Clin. Microbiol. 20 (1984) 936-941.

[21] M. Xilinas, J. Papavassiliou, N. Legakis, Selective medium for growth of Proteus, J. Clin. Microbiol. 2 (1975) 459.

[22] National Research Council (NRC), Nutrient Requirements of Dogs and Cats, The National Academies Press, Washington, DC, 2006https://doi.org/10.17226/10668.

[23] G. Biagi, I. Cipollini, A. Pompei, G. Zaghini, D. Matteuzzi, Effect of a Lactobacillus animalis strain on composition and metabolism of the intestinal microflora in adult dogs, Vet. Microb. 124 (1) (2007) 160-165.

[24] V. Biourge, C. Vallet, A. Levesque, R. Sergheraert, S. Chevalier, J.-L. Roberton, The use of probiotics in the diet of dogs, J. Nutr. 128 (12) (1998) 2730S-2732S. 